\title{
Myocardial Release of Hypoxanthine and Lactate During Percutaneous Transluminal Coronary Angioplasty
}

\author{
Patrick W. Serruys, MD, Harry Suryapranata, MD, Federico Piscione, MD, \\ Eef Harmsen, PhD, Marcel van den Brand, MD, Pim de Feyter, MD, \\ Paul G. Hugenholtz, MD, and Jan W. de Jong, PhD
}

\begin{abstract}
The response of myocardial lactate and hypoxanthine metabolism during percutaneous transluminal coronary angioplasty was studied in a series of 15 patients undergoing this procedure. A minimum of 4 balloon inflations was performed per patient with an average duration per occlusion of $49 \pm 11$ seconds (mean \pm standard deviation) for a total occlusion time of $192 \pm 40$ seconds.

Thermodilution coronary venous blood flow measured in the great cardiac vein decreased from control values of $72 \pm 4 \mathrm{ml} / \mathrm{min}$ (mean \pm standard error of the mean) to $47 \pm 10 \mathrm{ml} / \mathrm{min}$ with the fourth coronary occlusion $(p<0.005)$. Arteriovenous lactate and hypoxanthine showed peak differences during the reactive hyperemia after the first 2 occlusions which did not increase after subsequent occlusions. Within minutes after the procedure, lactate and hypoxanthine efflux was no longer seen, demonstrating the reversibility of the metabolic disturbances after repeated ischemia.

The results of this study indicate that there is no permanent alteration in lactate or hypoxanthine metabolism after percutaneous transluminal coronary angioplasty with $\mathbf{4}$ coronary occlusions of $\mathbf{4 0}$ to 60 seconds' duration, with a total occlusion time of $192 \pm \mathbf{4 0}$ seconds.
\end{abstract}

(Am J Cardiol 1989;63:45E-51E)

From the Catheterization and Cardiochemical Laboratories, Thoraxcenter, Erasmus University, Rotterdam, The Netherlands. This study was supported in part by CNR-NATO research fellowship 216.1095.

Address for reprints: Patrick W. Serruys, MD, Catheterization Laboratory, Thoraxcenter, P.O. Box 1738, 3000 DR Rotterdam, The Netherlands.
U ntil recently, the assessment of alteration in myocardial metabolism in humans early after an abrupt occlusion of a major coronary artery has not been feasible. Percutaneous transluminal coronary angioplasty (PTCA), however, now provides a unique opportunity to study the time course of these metabolic changes during the transient interruption of coronary flow by the balloon occlusion sequence in patients with 1-vessel disease and without angiographically demonstra ble collateral circulation. ${ }^{1,2}$ The need to detect any persisting metabolic or mechanical dysfunction becomes of even greater concern as the number of dilated vessels and the duration of balloon inflation tend to increase, thereby enhancing both the extent and the severity of ischemia. The risk exists that the damage induced by the intervention may exceed its benefit.

During and after ischemia, there is in the heart, as well as in other muscles, excessive adenosine triphosphate (ATP) breakdown. This degradation of ATP causes an efflux of breakdown products, which are able to pass through the cell membrane into the blood before significant amounts of enzymes appear. The purine derivatives adenosine, inosine and hypoxanthine are therefore thought to be early markers for ischemia. ${ }^{3}$ Because of high activities of adenosine deaminase and low amounts of nucleoside phosphorylase and xanthine oxidase in the heart and blood, hypoxanthine seems most promising as an early marker for myocardial ischemia. ${ }^{4}$

Recently, high-pressure liquid chromatography (HPLC) came into use for the determination of nucleosides and purine bases in the whole blood, ${ }^{5,6}$ facilitating the determination of purine derivatives, in particular hypoxanthine. This new technical development prompted us to investigate the myocardial release of hypoxanthine during coronary angioplasty.

Patients: All patients met the following criteria: a brief history of angina pectoris ( $<1$ year), an isolated obstructive lesion in 1 coronary vessel (the left anterior descending artery) and an accessible stenosis of $<1 \mathrm{~cm}$ in length. All patients were candidates for coronary artery bypass graft surgery because of disabling angina, but were selected for angioplasty rather than surgery because of their anatomy.

Fifteen patients ( 12 men and 3 women, aged 38 to 74 years) were studied. Of these, 4 were in New York Heart Association class II, 9 in class III and 2 in class IV. In all, 
the ejection fraction was $>50 \%$ and none of them had wall motion abnormalities on their diagnostic left ventriculograms at rest. Four transluminal dilatations were performed with a total duration of occlusion of $192 \pm 40$ seconds (mean \pm standard deviation). All patients in the study underwent successful reperfusion with the 4 episodes of PTCA. All patients in this study gave their informed consent and there were no complications directly related to the research procedure.

Percutaneous transluminal coronary angioplasty: PTCA was performed according to the technique of Gruentzig, with the equipment of Schneider, via the femoral route. In all cases the pressure gradient across the obstructive lesion was recorded before, during and after balloon inflation. The dilatation catheters were either the 20 to 30 or 20 to 37 models. The inflation pressure ranged from 2 to $12 \mathrm{~atm}$, whereas the individual duration of occlusion ranged from 40 to 60 seconds. Coronary angiography with nonionic contrast medium (metrizamide) was performed before and at the end of the PTCA procedurc.

Premedication consisted of aspirin, and all patients received $3 \mathrm{mg}$ of isosorbide dinitrate selectively into the left main coronary artery during control coronary arteriography, but the coronary flow measurements we report were not performed within the periods of the drug's effect

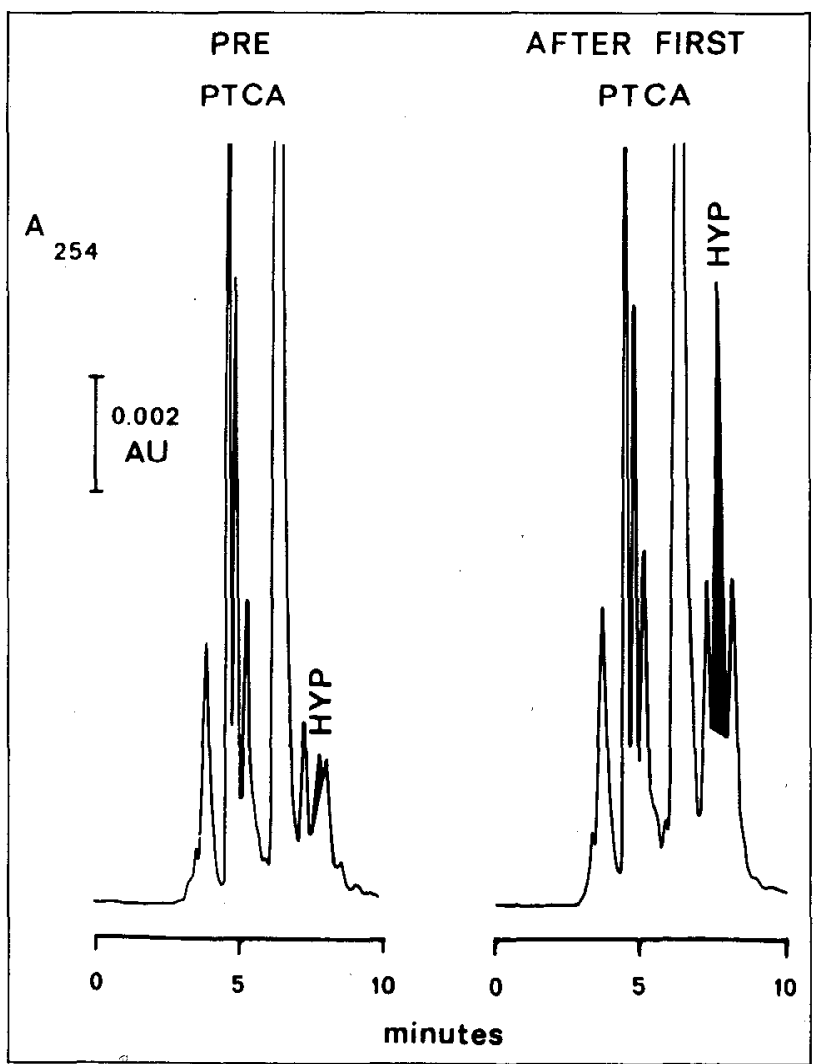

FIQURE 1. Isocratic high-pressure liquid chromatographic separation of nucleosides and purine bases from a patient before and after a single transluminal occlusion. $\mathbf{A U}=$ absorption units; HYP = hypoxanthine; PTCA = percutaneous transluminal coronary angioplasty. on the coronary circulation. Therapy with $\beta$-blocking drugs was not discontinued. During the procedure, heparin and low molecular weight dextran were administered intravenously.

Lactate and hypoxanthine determinations: Blood samples were obtained from the great cardiac vein and the left coronary artery at 6 consecutive measurement periods: before the PTCA procedure, 5 to 10 seconds after each transluminal occlusion and 5 minutes after termination of the PTCA procedure. Five minutes were allowed between each dilatation for recovery.

Blood $(1.5 \mathrm{ml})$ for lactate measurements was rapidly deproteinized with an equal volume of cold $8 \%$ perchloric acid $\left(\mathrm{HClO}_{4}\right)$ and centrifuged. After centrifugation, the supernatant fluids were stored at $-20^{\circ} \mathrm{C}$. Lactate in the supernatant was analyzed enzymatically according to Apstein et $\mathrm{al}^{7}$ with the AutoAnalyzer (Technicon, Tarrytown, New York). Standard curves were made with lithium lactate in $4 \% \mathrm{HClO}_{4}$

An isocratic HPLC system was used for the estimation of purine nuclcosides and oxypurines in blood. ${ }^{6}$ Use was made of a reversed-phase column. Because nucleotides derived from erythrocytes affected the separation, these compounds had to be removed. The method of Chatterjee et al was used ${ }^{8}$ with some minor differences. We applied $1.5 \mathrm{ml}$ of the deproteinized, neutralized blood sample onto a prewashed column of $\mathrm{Al}_{2} \mathrm{O}_{3}(0.6 \mathrm{~g})$ in a Pasteur pipette, and eluted it with $5.0 \mathrm{ml} 10 \mathrm{mmol} /$ liter Tris/HCl, $\mathrm{pH}$ 7.4. For faster elution, a vacuum was applied to a sampling manifold. Twelve samples were treated at the same time. A Waters M 6000 HPLC* was used with a WISP 710 B autosampler,* a model 440 UVdetector* fixed at $254 \mathrm{~nm}$ wavelength connected to a BD 41 recorder. $^{\dagger}$ A $4 \mathrm{~mm}$ I.D. $\times 30 \mathrm{~cm}$ prepacked $\mu$ Bondapak/ $\mathrm{C}_{18}$ column,* particle size $10 \mu \mathrm{m}$, was used in these studies. Chromatographic conditions were adapted from earlier work ${ }^{9}: 200 \mu \mathrm{l}$ samples were eluted from this column with $10 \mathrm{mmol} /$ liter $\mathrm{NH}_{4} \mathrm{H}_{2} \mathrm{PO}_{4} / \mathrm{CH}_{3} \mathrm{OH}$ (10:1, $\mathrm{v} / \mathrm{v}$ ), pH 5.50. The flow rate was $60 \mathrm{ml} /$ hour (Fig. 1).

Flow and resistance measurements: Grcat cardiac vein blood flow was measured by the continuous thermodilution method before and after the PTCA procedure as well as during each transluminal occlusion. In the beginning of the investigation the location of the external thermistor, in the great cardiac vein, was verified by injection of $3 \mathrm{ml}$ of contrast material. Each recording of blood flow during coronary angioplasty began before balloon inflation and was interrupted at the moment of balloon deflation. Coronary vascular resistance (CVR) was calculated for great cardiac vein ${ }^{10}$ using the mean arterial pressure (MAP) and blood flow in the great cardiac vein:

$$
\mathrm{CVR}=\mathrm{MAP} / \text { Flow }(\mathrm{mm} \mathrm{Hg} / \mathrm{ml} / \mathrm{min})
$$

Statistical analysis: Results are expressed as mean \pm standard error of the mean. Comparison between results before and after PTCA and occlusion conditions were evaluated using analysis of variance for repeated measurements. When overall significance was found, multi-

*Millipore Waters, Bedford, Massachusetts.

†Kipp en Zonen, Delft, the Netherlands. 
ple comparisons were significantly different at the 0.05 level.

\section{RESULTS}

Coronary hemodynamic measurements: The results of the coronary hemodynamic observations are summarized in Figure 2 and Table I. During the initial dilatation, the mean duration of balloon inflation was $44 \pm 4$ seconds. During the subsequent dilatations the duration of inflation was slightly increased up to $49 \pm 6$ seconds.
Occlusion pressure did not change throughout these occlusion times of 40 to 60 seconds and there was a high degree of reproducibility of the occlusion pressure during these successive occlusions (Table I). The mean blood flow in the great cardiac vein before the first inflation was $72 \pm 4 \mathrm{ml} / \mathrm{min}$, decreasing to $47 \pm 10 \mathrm{ml} / \mathrm{min}$ (p $<0.003$ ) during the fourth inflation and increasing slightly to $93 \pm 8 \mathrm{ml} / \mathrm{min}(\mathrm{p}<0.03)$ after completion of the PTC $\Lambda$ procedure (Table I). Great cardiac vein coronary vascular resistance was $1.42 \pm 0.18 \mathrm{~mm} \mathrm{Hg} / \mathrm{ml} / \mathrm{min}$
FIGURE 2. Changes in great cardiac vein flow and resistance during 4 transluminal occlusions, GCV = great cardiac vein; Post $=$ postangioplasty; Pre $=$ before angioplasty; PTCA = percutaneous transluminal coronary angioplasty.

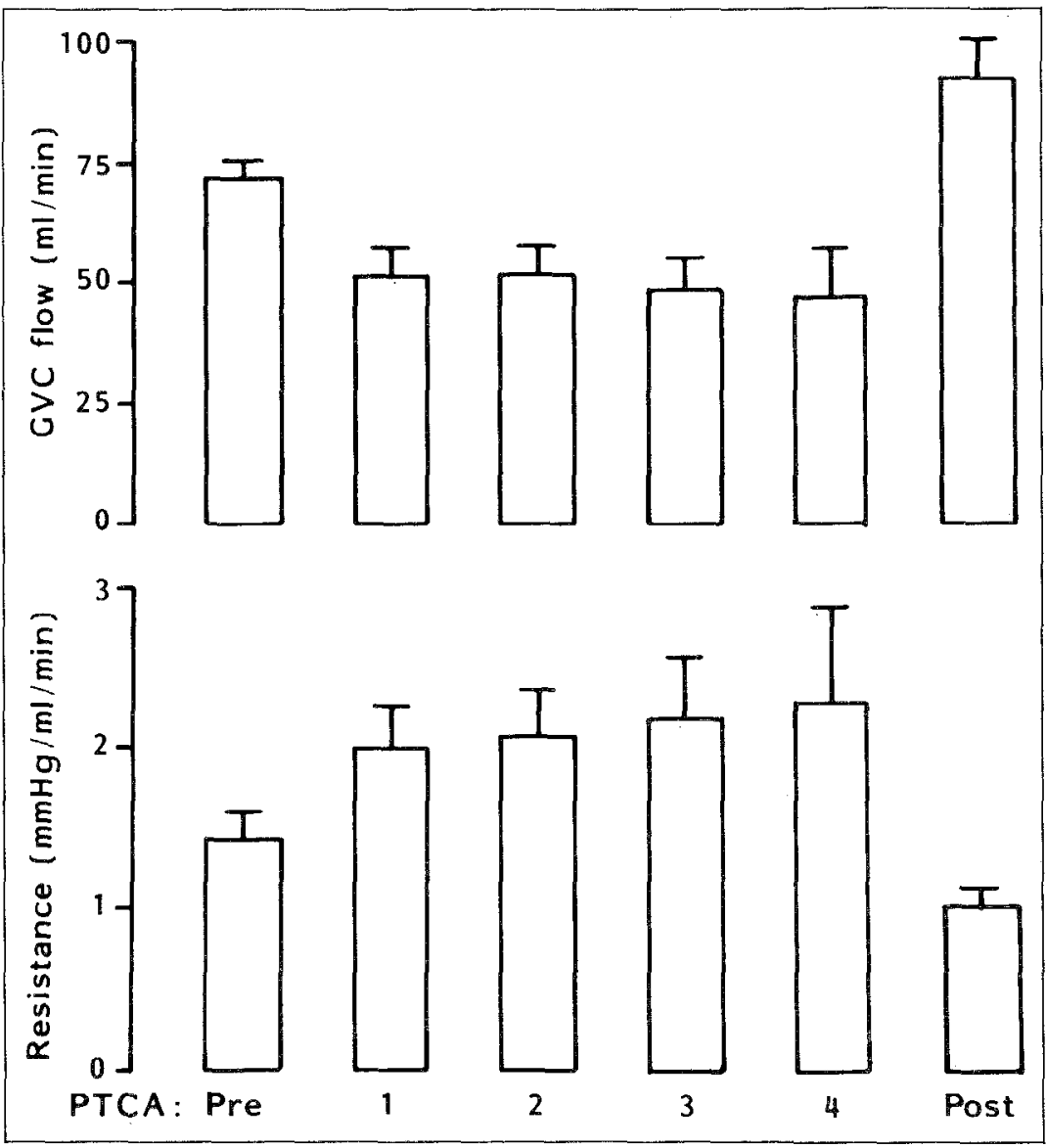

TABLE I Coronary Hemodynamics and Metabolic Disturbances During Sequential Transluminal Occlusion (15 Patients)

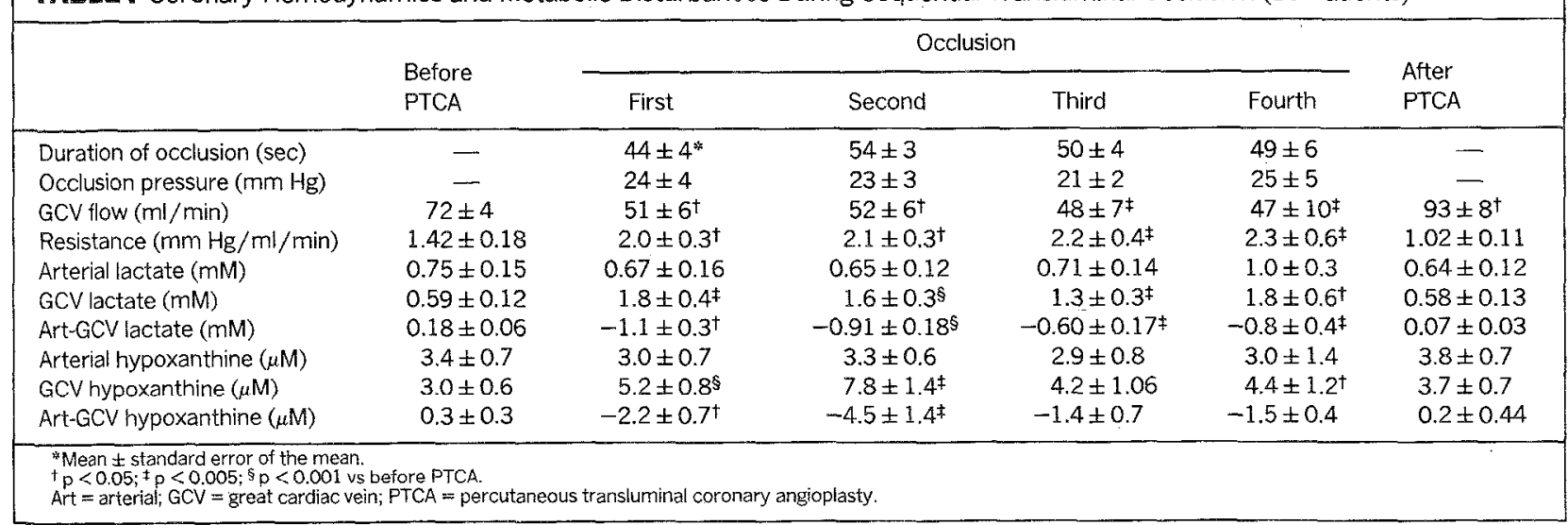


before balloon inflation, $2.3 \pm 0.6$ by the end of the fourth inflation $(p<0.005)$ and $1.02 \pm 0.11$ after completion of the PTCA procedure (Table I).

Lactate and hypoxanthine metabolism: The arteriovenous lactate measurements are listed in Table I and shown in Figure 3. The control measurements showed a difference of $+0.18 \mathrm{mM}$, which decreased to -1.1 and $-0.91 \mathrm{mM}$, after the first and the second dilatations, respectively. After the third dilatation the lactate difference was $-0.60 \mathrm{mM}$, which was not significantly different from the values recorded after the first and the second dilatation. As a first approximation, the amount of lactate lost from the ischemic tissue during the 4 consecutive occlusions seems to be more or less constant and at least did not increase with the time. During the 4 consecutive transluminal occlusions, an average increase of hypoxanthine in the great cardiac vein, from $3.0 \pm 0.6$ to $5.6 \pm 1.1$ $\mu \mathrm{M},(\mathrm{p}<0.01)$ was observed, which fell off after completion of the PTCA procedure. The arterial levels of these compounds remained constant during transluminal occlusion. The myocardial arterial-great cardiac vein difference of hypoxanthine changed from $0.3 \pm 0.3 \mu \mathrm{M}$ before angioplasty at rest to $-2.4 \pm 1.2 \mu \mathrm{M}(\mathrm{p}<0.01)$ during sequential transluminal occlusions. Even if not statistically significant, a trend for hypoxanthine release to be reduced during occlusions 3 and 4 compared with occlusion 1 or 2 was observed. Significant production of hypoxanthine, calculated either as arteriovenous differ- ence or extraction, only took place after the first 2 transluminal occlusions, whereas hypoxanthine release was absent 5 minutes after completion of the PTCA procedure.

\section{DISCUSSION}

Purine versus lactate release as a marker for ischemia during transluminal coronary occlusion in humans: Ischemia can be defined as a situation in which coronary blood flow cannot meet the tissue demand. ${ }^{11}$ As a consequence of the ensuing oxygen deficiency, the balance between ATP production and usage is disturbed. ${ }^{12}$ ATP (and creatine phosphate) levels fall, ${ }^{3,13}$ creatine, adenosine diphosphate (ADP), phosphate and hydrogen ion levels increase, ${ }^{14-16}$ glycolysis rate is enhanced ${ }^{17,18}$ and lactate levels rise. Shortly thereafter, potassium ion, hydrogen ion and lactate are released into the coronary venous blood.

ATP is converted to ADP and adenosine monophosphate (AMP), which is broken down to adenosine, inosine, hypoxanthine, xanthine and urate (Fig. 4). The AMP catabolites pass the cell membrane. ${ }^{19-22}$ Thus, a slight decrease of ATP results in an immediate increase in AMP catabolites, and this release can be used to monitor myocardial ATP breakdown.

We believed; therefore, that measuring myocardial arteriovenous differences of blood hypoxanthine levels could give insight into the metabolic state of the heart ${ }^{4}$;

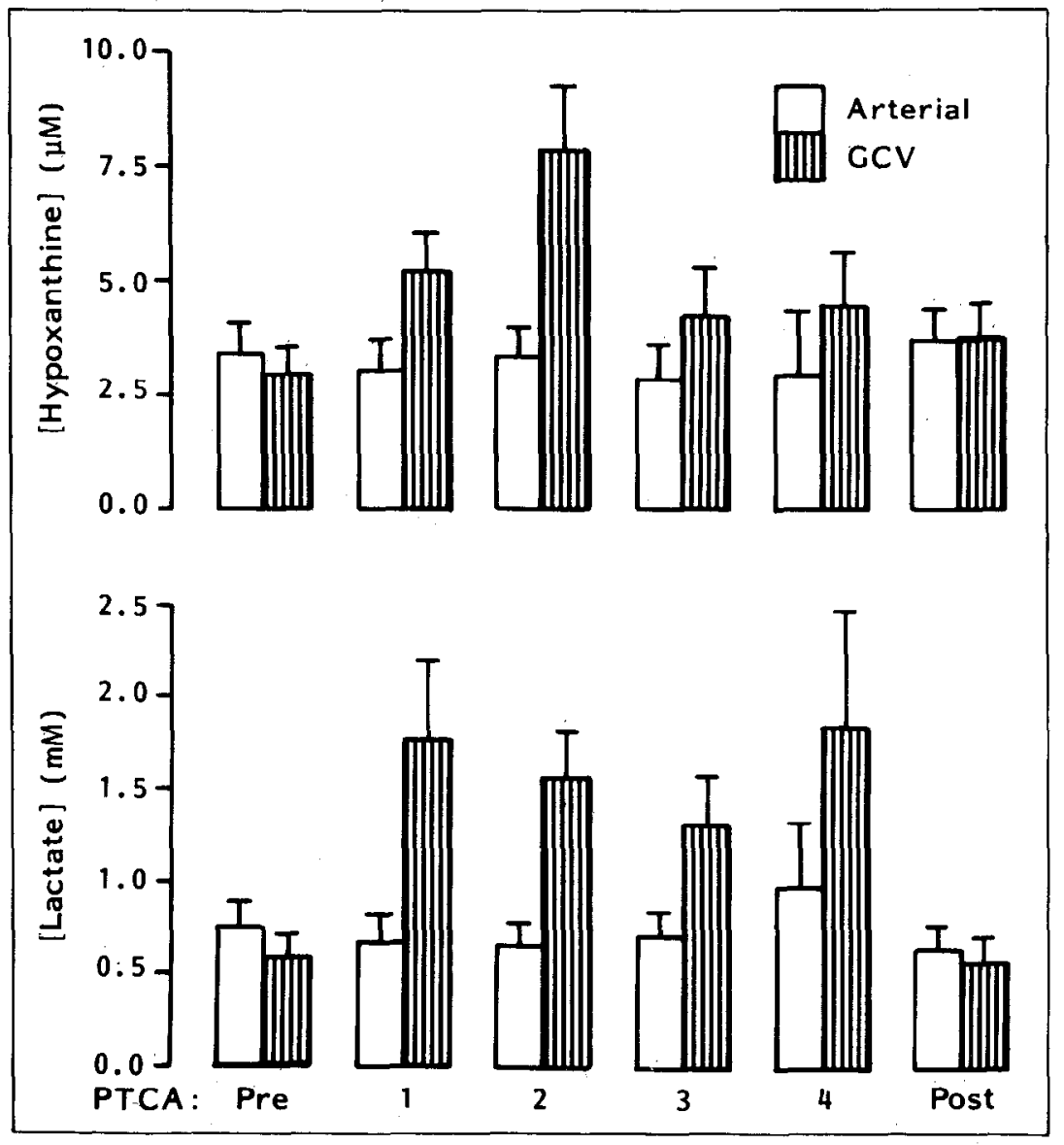

FIGURE 3. Changes in arterial and venous concentration of hypoxanthine and lactate during transluminal occlusion. Abbreviations as in Figure 2. 
the method used here makes it possible to measure a number of AMP catabolites in blood. In fact, since the $1960 \mathrm{~s}$, several studies have discussed the release of purine

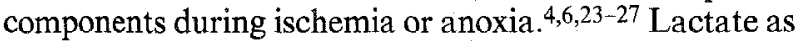
a marker of ischemia, has several disadvantages. During normoxia, lactate is preferentially taken up by the heart. ${ }^{28}$ In fact, lactate released from a local ischemic area can be metabolized by the surrounding normoxic tissue. ${ }^{17}$ The formation and removal of lactate is also influenced by blood fatty acid levels, acidosis and by
FIGURE 4. Myocardial adenosine triphosphate (ATP) catabolism. The main pathways are: (1) ATPase; (2) adenylate kinase; (3) 5'-nucleotidase; (4) adenosine deaminase; (5) mucleoside phosphorylase; (6) Xanthine oxidase (a)/dehydrogenase (b).
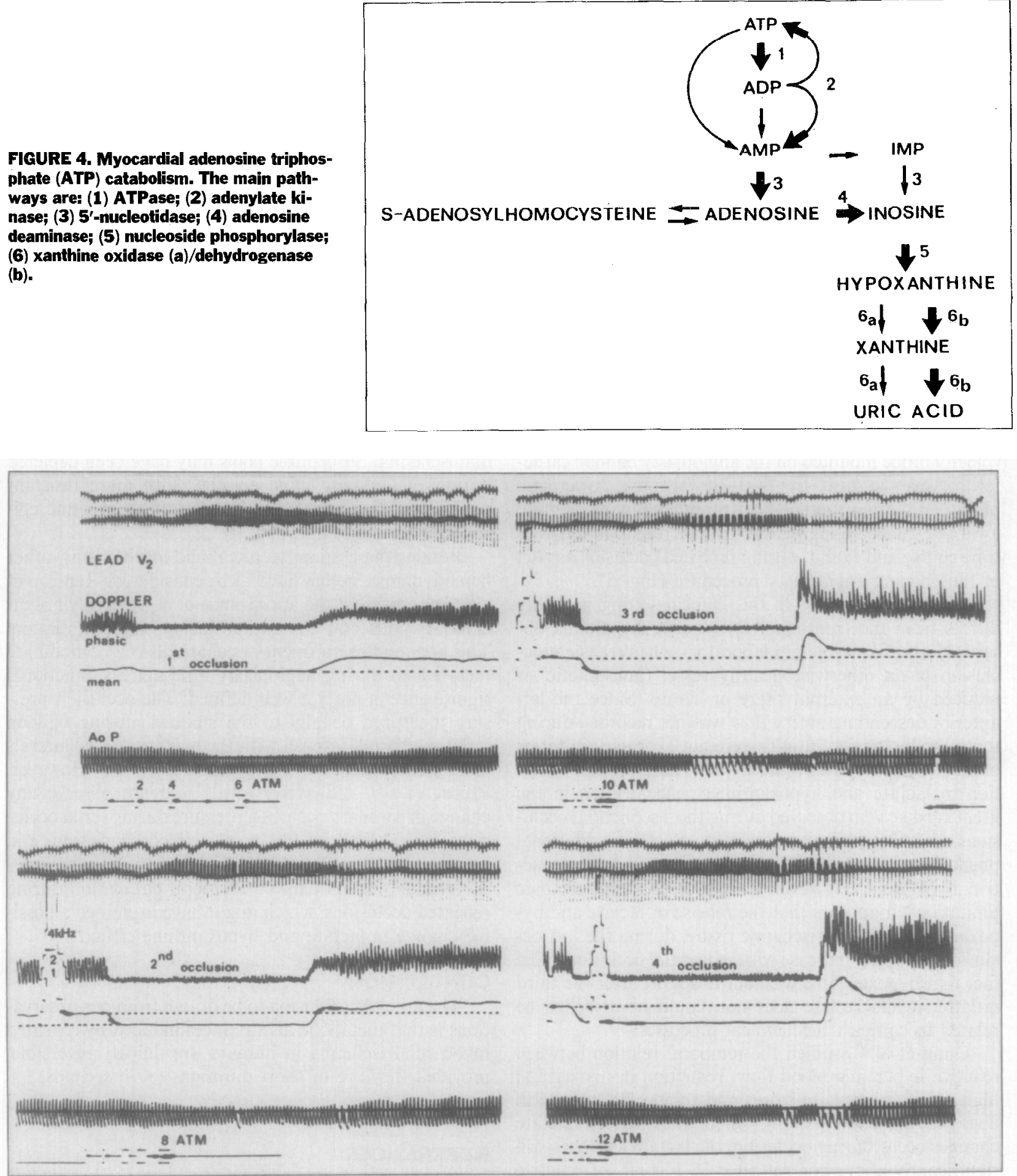

FICURE 5. Examples of mean and phasic intracoronary Doppler signal recorded before, during and after balloon inflation. Reactive hyperemia occurs after each balloon deflation but its extent and time course are variable during the sequentlal occlusions and thereby could affect the concentration of the ischemic catabolites during the sampling period. 
hyperglycemia, ${ }^{29}$ all metabolic conditions likely to be present during angioplasty.

Time of blood withdrawal and potential methodologic limitations: In our patients, blood samples were obtained 5 to 10 seconds after the start of deflation. Coronary sinus potassium ion concentration has been measured continuously in patients undergoing angioplasty of significant stenoses of the left anterior descending coronary arteries..$^{30}$ The recordings obtained from these patients showed that, although coronary sinus potassium ion levels did not change significantly during coronary occlusion, a transient increase occurred when the occlusion was removed. After reduction of the pressure in the balloon, the coronary sinus potassium ion levels began to increase within 8 seconds. This fits approximately with the timing of peak reactive hyperemia observed by ourselves and by Rothman et $\mathrm{al}^{31}$ and corresponds with the timing of blood withdrawal in this study using a thermodilution technique.

More pronounced reactive hyperemia developed when the residual functional coronary stenosis associated with the deflated PTCA balloon was reduced by subsequent dilatation. ${ }^{1,31}$ In a previous study, we $\mathrm{e}^{1}$ demonstrated that the mean hyperemic increase in great cardiac vein flow was $55 \%$ after the first dilatation and $91 \%$ after the third dilatation. We recently used an intracoronary Doppler velocity probe mounted on the angioplasty balloon catheter to analyze beat by beat the reactive hyperemic phase. ${ }^{32}$ This new methodologic approach made us more aware of the changing pattern of hyperemia, in terms of time course and extent, during repeated occlusion as part of the ongoing angioplasty procedure (Fig. 5).

What was observed in this clinical setting probably differs from the (reproducible) reactive hyperemia observed in the experimental laboratory when transient occlusion of an otherwise healthy vessel (nonstenotic) is induced by an external snare or clamp. Since the left anterior descending artery flow was not recorded during the sampling period, results were not expressed in terms of lactate and hypoxanthine efflux. Therefore, the variation in lactate and hypoxanthine concentration in the great cardiac vein observed during the 4 sequential occlusions might have been considerably affected by dilutional phenomena related to the changing pattern of the reactive hyperemia. However, despite these methodologic limitations, it appears that the release of lactate and hypoxanthine from the ischemic tissue, during the last occlusions, does not increase with sequential occlusions. The fact that hypoxanthine washout drops off after the third inflation while lactate does not, could nevertheless be related to complex biochemical processes.

Dunn et al, ${ }^{33}$ studied the temporal relation between reactive hyperemic blood flow, reduction in myocardial high-energy phosphate stores and removal of lactate in dogs. In the endocardium, where the greatest lactate changes occur during occlusion, the lactate level was still significantly above control after 30 seconds of reactive hyperemia when approximately three-fourths of the response had occurred. In contrast, a return of the highenergy phosphate stores to control level was already ap- parent at the time of the peak hyperemic flow when only one-fourth of the response had occurred. We speculate that different responses to ischemia of the glycolytic and purine pathways are responsible for the somewhat different lactate and hypoxanthine profiles observed (Fig. 3). The great cardiac vein lactate and hypoxanthine returned to control levels at the end of the PTCA procedure. This indicates that the metabolic changes induced by PTCA are quickly reversible.

Metabolism after repetitive episodes of brief ischemia: Previous work ${ }^{34,35}$ indicates that repetitive episodes of brief ischemia do not produce a cumulative depletion of high-energy phosphate compounds. The content of nucleotide pools at any point in time is determined by the rate of synthesis vs demand. The failure to demonstrate a progressive decrease in nucleotide pools during subsequent ischemic episodes after an initial ischemic episode might be explained by a decreased degradation of nucleotides during the subsequent ischemic episodes.

The mechanism for the putative decrease in coronary nucleotide degradation rate during subsequent episodes of ischemia is unclear, but several explanations have been proposed to account for this finding. ${ }^{36-39}$ There is growing evidence for compartmentation of myocardial nucleotide pools. ${ }^{36,37}$ The different compartments in the cell may have different susceptibilities to depletion during myocardial ischemia. Susceptible pools may have been depleted during the first ischemic episode, with more resistant pools remaining intact during subsequent ischemic episodes of the same duration.

Besides these adaptive metabolic mechanisms, other hemodynamic factors have to be considered. Rentrop et $\mathrm{al}^{40}$ demonstrated the appearance of a previously absent coronary collateral circulation during balloon inflation. This apparent recruitment of collaterals might modulate metabolism during angioplasty although its functional significance is not yet well defined. The occlusion pressure measured distally to the stenosis, during balloon inflation, correlates well with the existence of collaterals demonstrable before or during angioplasty. ${ }^{41,42}$ However, Probst et $\mathrm{al}^{41}$ and Meier et $\mathrm{al}^{42}$ did not observe any change in coronary occlusion pressure during serial occlusions. The absence of any increase in coronary sinus and great cardiac vein flow during serial occlusions precludes the gradual recruitment of collateral circulation during repeated occlusions, which might have explained a possible change in lactate and hypoxanthine efflux.

\section{CONCLUSION}

The crucial conclusion to be drawn from our observations is that metabolic disturbances induced by repeated myocardial ischemia in humans are quickly reversible, provided they are of short durations ( $<90$ seconds).

\section{REFERENCES}

1. Serruys PW, Wijns W, Van den Brand M, Mey S, Slager C, Schuurbierș JCH, Hugenholtz PG, Brower RW. Left ventricular performance, regional blood flow, wall motion and lactate metabolism during transluminal angioplasty. Circulation $1984,70: 25-36$.

2. Serruys PW, van den Brand M, Brower RW, Hugenholtz PG. Left ventricular 
hemodynamics, regional blood flow and lactate metabolism during balloon occlusion: can we alter the sequence of ischemic events? In: Rutishauser W, Roskam MW, eds. Silent Myocardial Ischemia. Berlin, Heidelberg, New York, Tokyo. Springer-Verlag, 1984:37-44.

3. de Jong JW. Biochemistry of acutely ischemic myocardium. In: Schaper W, ed The Pathophysiology of Myocardial Perfusion. Amsterdam: Elsevier/North-Hol land Biomedical Press, 1979:719-750.

4. Remme WJ, de Jong JW, Verdouw PD. Effects of pacing-induced myocardia ischemia on hypoxanthine efflux from the human heart. Am J Cardiol 1977;40. $55-62$.

5. Hartwick RA, Krstulovic AM, Brown PR. Identification and quantitation of nuclcosides, bases and other UV-absorbing compounds in scrum, using reversedphase high-performance liquid chromatography. II Evaluation of human sera. Chromatogr 1979;186:659-676.

6. Harmsen E, de .Iong. IW, Serruys PW. Hypoxanthine production by ischemic heart demonstrated by high pressure liquid chromatography of blood purin nucleosides and oxypurines. Clin Chim Acta 1981;115:73-84.

7. Apstein CS, Puchner E, Brachfeld N. Improved automated lactate determination. Anal Biochem 1979:38:20-34.

8. Chatterjee SK, Bhattacharya M, Barlow JJ. A simple, specific radiometric assay for 5'-nucleotidase. Anal Biochem 1979;95:497-506.

9. de Jong JW, Keijzer E, Uitendaal MP, Harmsen E. Further purification of adenosine kinase from rat heart using affinity and ion-exchange chromatography Anal Biochem 1980;101:407-412.

10. Mehta J, Pepine CJ. Effect of sublingual nitroglycerin on regional flow in patients with and without coronary disease. Circulation 1978:58:803-807.

11. Manning AS, Hearse DJ, Dennis SC, Bullock GR, Coltard DJ. Myocardial ischemia: an isolated, globally perfused rat heart model for metabolic and pharmacological studies. Eur $J$ Cardiol 1980;11:1-21.

12. Wilson DF, Owen CS, Erecinska M. Quantitative dependence of mitochondrial oxidative phosphorylation on oxygen concentration. A new mathematical model. Arch Biochem Biophys 1979;195:494-504.

13. Danforth WH, Naegle S, Bing RJ. Effects of ischemia and reoxygenation on glycolytic reactions and adenosine triphosphate in heart muscle. Circ Res 1960,8:965-971.

14. Garlick BP, Radda GK, Seeley PJ. Studies of acidosis in the ischaemic heart by phosphorus nuclear magnetic resonance. Biochem J 1979;184:547-554

15. Hearse DJ. Oxygen deprivation and early myocardial contractile failure.

Reassessment of the possible role of adenosine triphosphate. Am J Cardiol 1979;44:1115-1120.

16. Hearse DJ, Crome R, Yellon DM, Wyse R. Metabolic and flow correlates of myocardial ischemia. Cardiovasc Res 1983:17:452-458.

17. Apstein CS, Deckelbaum L, Mueller M, Hagopian L, Hood WB. Graded global ischemia and reperfusion. Circulation 1979;55:864-872.

18. Neely JR, Liedke AJ, Whitmer 'IJ, Rovetto MJ. Relationship between coronary flow and adenosine triphosphate production from glycolysis and oxidative metabolism. Recent Adv Studies Cardiac Structure Metab 1975;8:301-321. 19. de Boer LWV, Ingwall JS, Kloner RA, Braunwald E. Prolonged derangements of canine myocardial purine metabolism after brief coronary artery occlusion not associated with anatomic evidence of necrosis. Proc Natl Acad Sci USA $1980,77.5471-5475$.

20. de Jong JW, Harmsen E, de Tombe PP, Keijzer E. Release of purine nucleosides and oxypurines from the isolated perfused rat heart. In: Chazov E Saks V, Rona G, eds. Advances in Myocardiology. vol. 4. New York: Plenum, 1983:339-345

21. Schrader J, Haddy FJ, Gerlach E. Release of adenosine, inosine and hypoxanthine from the isolated guinea pig heart during hypoxia, flow-autoregulation and reactive hyperemia. Pflügers Arch 1979;369:251-257.

22. Berne RM. The role of adenosine in the regulation of coronary blood flow.
Circ Res 1980;47:807-813.

23. Fox AC, Reed GE Mellman H, Silk BB. Release of nucleosides from canineand human hearts as an index of prior ischemia. Am J Cardiol 1979,43:52-57.

24. Kugler G. Myocardial release of lactate, inosine and hypoxanthine during atrial pacing and exercise-induced angina. Circulation 1979,59:43-49.

25. Edlund A, Berglund B, van Dorne B, Kaÿser L, Nowak J, Patrono C, Sollev $A$, Wennalm A. Coronary flow regulation in patients with ischemic heart disease: release of purines and prostacyclin and the effect of inhibitors of prostaglandin formation. Circulation 1985;71:1113-1120.

26. Schoenberg MH, Fredholm BB, Hohlbach G. Changes in acid-base status, lactate concentration and purine metabolics during reconstructive aortic surgery. Acta Chir Scand 1985;151:227-233.

27. de Jong JW, Verdouw PD, Remme WJ. Myocardial nucleoside and carbohydrate metabolism and hemodynamics during partial occlusion and reperfusion of nig coronary artery. I $\mathrm{Mol}$ Cell Cardiol 1977;9:297-312.

28. Drake AJ, Haines JR, Noble MIM. Preferential uptake of lactate by the normal myocardium in dogs. Cardiovasc Res 1980;14:65-77.

29. Verdouw PD, Stam H, Remme WJ. Fundamental validity and clinical usefulness of myocardial lactate balance during ischaemia. A comparison with other biochemical markers. In: Moret PR, Weber J, Haissly JC, Denolin H, eds. Lactate-Physiologic, Methodologic and Pathologic Approach. Springer-Verlag, Berlin, 1980;207-223.

30. Webb SC, Rickards AF, Poole-Wilson PA. Coronary sinus potassium concentration recorded during coronary angioplasty. Br Heart J 1983;50:146-148. 31. Rothman MT, Baim DS, Simpson JB, Harrison DC. Coronary hemodynamics during percutaneous transluminal coronary angioplasty. Am $J$ Cardiol 1982,49:1615-1621.

32. Serruys PW, Zijlstra F, Reiber JHC, van Ommeren J, de Ruiter R, Ligthart $\mathrm{J}$. Assessment of coronary flow reserve during angioplasty using a Doppler tip balloon catheter. Comparison with digital subtraction cineangiography (abstr). JACC 1987;9:197 A

33. Dunn RB, McDonough KM, Griggs DM Jr, High energy phosphate store and lactate levels in different layers of the canine left ventricle during reactive hyperemia. Circ Res 1979;44:788-795.

34. Swain JL, Sabina RL, Hines JJ, Greenfield JC Jr, Hulnes EW. Repelitive episodes of brief ischemia ( $12 \mathrm{~min}$ ) do not produce a cumulative depletion of high energy phosphate compounds. Cardiovasc Res 1984;18:264-269.

35. Verdouw PD, Remme WJ, de Jong JW, Breeman WAP. Myocardial substrate utilization and hemodynamics following repeated coronary flow reduction in pigs. Basic Res Cardiol 1979;74:477-493.

36. Gudbjarnason S, Mathes P, Ravens KG. Functional compartmentation of ATP and creatine phosphate in heart muscle. $J$ Mol Cell Cardiol 1970:1:325-329.

37. Schrader J, Gerlach E. Compartmentation of cardiac adenine nucleotides and formation of adenosine. Pflügers Arch 1976;367:129-135.

38. Swain JL, Sabina RL, McHale PA, Greenfield JC Jr, Holmes EW. Pro longed myocardial nucleotide depletion after brief ischemia in the open-chest dog. Am J Physiol 1982;242:818-826.

39. Vial C, Font B, Goldschmidt D, Pearlman AS, Delaye J. Regional myocardial energetics during brief periods of coronary occlusion and reperfusion: comparison with S-T segments changes. Cardiovasc Res 1978;12:470-476.

40. Rentrop KP, Cohen M, Blanke H, Phillips RA. Changes in collateral channe filling immediately after controlled coronary artery occlusion by an angioplasty balloon in human subjects. $J A C C$ 1985;5:587-592.

41. Probst $P$, Zangl $W$, Pachinger $O$. Relation of coronary arterial occlusion pressure during percutaneous transluminal coronary angioplasty to presence of collaterals. Am J Cardiol 1985:55:1264-1269.

42. Meier B, Luethy $P$, Finci L, Steffenino GD, Rutishauser W. Coronary wedge pressure in relation to spontaneously visible and recruitable collaterals. Circulation $1987 \cdot 75 \cdot 906-913$ 